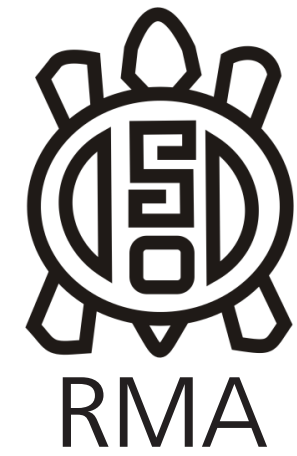

Arqueología

\title{
Hacia la comprensión de un espacio multipropósito: Resultados de la prospección arqueológica en Río Las Salinas 2 (Tucumán)
}

\author{
Towards the understanding of a multipurpose space: Results of the \\ archaeological survey in Río Las Salinas 2 (Tucumán)
}

\section{Carolina Somonte* y Carlos Baied**}

* CONICET. Instituto de Arqueología y Museo. Facultad de Ciencias Naturales e Instituto Miguel Lillo. Universidad Nacional de Tucumán, Tucumán, Argentina.

E-mail: carosomonte@hotmail.com

${ }^{* *}$ Centro de Investigaciones en Ecología Histórica (CIEH). Facultad de Ciencias Naturales e Instituto Miguel Lillo. Universidad Nacional de Tucumán, Tucumán, Argentina.

E-mail: cbaied@csnat.unt.edu.ar

\begin{abstract}
Resumen
En este trabajo se presentan los resultados de una prospección intensiva y extensiva de la cantera-taller Río Las Salinas 2, realizada en el marco de una evaluación de impacto arqueológico. La prospección pedestre y de cobertura total involucró el trazado de transectas paralelas distribuidas sobre una superficie de 620 has. Durante el recorrido se completaron fichas diseñadas tanto para una descripción paisajística del contexto, como así para una caracterización arqueológica de cada tipo de hallazgo. Estos hallazgos fueron agrupados en categorías de estructuras arquitectónicas, concentración de material lítico, arte rupestre, artefactos aislados, así como también de combinaciones entre las mismas. Esta prospección posibilitó la identificación de un extenso espacio altamente circulado, en el que además del aprovisionamiento lítico, se registraron evidencias de ocupaciones temporarias y demarcación de espacios que permitieron profundizar la caracterización de la persistencia en el uso de RLS2. La evidencia arqueológica en su conjunto reafirma la interpretación acerca de la complejidad funcional de esta cantera-taller, como espacio multipropósito de gran extensión.
\end{abstract}

Palabras clave: Táctica pedestre; Superficies arqueológicas; Registro arqueológico lítico; Persistencia ocupacional.

\section{Abstract:}

This paper presents the results of an intensive and extensive survey of the Rio Las Salinas 2 quarry-workshop, carried out as part of an archaeological impact assessment. The pedestrian and full-coverage survey involved the layout of parallel transects distributed over an area of 620 ha. During the survey, data sheets were completed, designed both for a landscape description of the context and for an archaeological characterization of each type of finding. These findings were grouped into categories of architectural structures, lithic material, rock art, isolated artifacts, as well as combinations between them. This survey allowed identifying an extensive and highly circulated space, in which, in addition to lithic supply, there was evidence of temporary occupation and demarcation of spaces, leading to further characterization of the persistence in the use of RLS2. The archaeological evidence as a whole reaffirms/ confirms the interpretation of the functional complexity of this quarry-workshop as a large multipurpose space.

Keywords: Pedestrian tactic; Archaeological surfaces; Lithic archaeological record; Occupational persistence

\section{Introducción}

A $5 \mathrm{~km}$ al sudoeste de la localidad de Amaicha del Valle (Tucumán, Argentina) atraviesa a la Ruta Provincial $n^{\circ}$ 357 el río Las Salinas, espacio que fue motivo de interés (internacional, nacional, provincial y comunitario) para el desarrollo de un emprendimiento de energía solar - de capital extranjero- de gran envergadura. Este proyecto planteaba la instalación de una planta fotovoltaica de conexión a red de $200 \mathrm{MWac}$ de potencia en el punto de interconexión, sobre una superficie de glacis cuyas dimensiones superan las 620 has. La obra civil de este emprendimiento proponía el acondicionamiento general del terreno; la realización de caminería, colocación de postes hincados en el suelo directamente sin utilización de cemento; instalación de cableado, construcción de dos edificios (una sala de control y un edificio de administración), instalación de estaciones meteorológicas 
y áreas destinadas al acopio de materiales (Baied, 2017). El espacio propuesto para el emprendimiento coincidía, en su totalidad, con el emplazamiento de la cantera-taller Río Las Salinas 2 (RLS2) y un sector contiguo al que hemos denominado RLS3.

RLS2 conforma uno de los ámbitos de aprovisionamiento de recursos líticos, característicos de un sector de los valles intermontanos del NOA (Somonte y Baied, 2011), donde no sólo tuvo lugar la obtención, explotación y producción lítica (Somonte y Baied, 2018). Se trata de una extensa superficie de glacis que presenta condiciones geomorfológicas de estabilidad variable, sobre la que se desarrolla un pavimento. Las investigaciones arqueológicas en el área de estudio, permiten sostener que los pavimentos manifiestan una preservación diferencial que afecta, a su vez, al registro arqueológico (Somonte y Baied, 2017). En los distintos sectores de estos pavimentos, las cubiertas detríticas, afectadas por barniz de las rocas, presentan variaciones en el arreglo, litología, forma y tamaño de los fragmentos. El registro lítico en RLS2 se encuentra expuesto en superficie, resultado de procesos postdepositacionales. Las investigaciones se concentraron, hasta el momento, en lugares puntuales donde se emplazan áreas de talleres líticos, soportes con arte rupestre, estructuras arquitectónicas diversas y artefactos aislados. Las dataciones mediante VML (varnish microlamination) realizadas sobre el barniz vinculado a este registro lítico, sumado a la evidencia arqueológica, ponen de manifiesto la presencia de ocupaciones humanas en RLS2 desde finales del Pleistoceno y a lo largo del Holoceno (Adris, 2012; Baied y Somonte, 2013; Somonte y Baied, 2018, 2011). Desde hace más de 10.000 años, RLS2 formó parte del repertorio de los lugares utilizados, explotados, visitados por grupos cazadores y, posteriormente, agro-pastoriles. Allí tuvieron lugar, en forma conjunta, tareas típicas de una canterataller (como el aprovisionamiento, acopio de recursos líticos y producción lítica), como así también otras actividades económicas específicas (i.e. procesamiento de recursos maderables, animales y vegetales) y simbólicas (grabados en soportes rocosos), que nos invitan a considerar a la cantera-taller RLS2, como un espacio multipropósito (Adris, 2013; Germano, 2016: Germano et al., 2017; Somonte y Baied, 2018). Este registro, además, permite postular a RLS2 como un conjunto de espacios persistentes, donde los artefactos y los soportes con arte rupestre dan cuenta de la preservación de diferentes historias de uso de ese lugar. La complejidad de estos espacios es lo que, a su vez, permite que sean considerados como palimpsestos, marcados por una convivencia horizontal de conjuntos de artefactos (en sentido amplio) con historias postdepositacionales y cronológicas diferentes (Somonte y Baied, 2017).

La naturaleza superficial del registro arqueológico de RLS2, marca la vulnerabilidad de este espacio a ser intervenido por cualquier emprendimiento que involucre el desbroce de la superficie, que conduciría a la pérdida total del patrimonio arqueológico. En este contexto, la necesidad de implementar estrategias metodológicas que combinaran los intereses de nuestros proyectos de investigación con la urgencia del estudio de impacto arqueológico, nos llevó a plantear una prospección arqueológica de cobertura total, mediante la táctica pedestre, sobre la extensión de RLS2. Si bien ya habíamos realizado prospecciones asistemáticas allí, no contábamos aún, con un relevamiento arqueológico cabal de este glacis de gran extensión.

La prospección arqueológica en RLS2 fue diseñada teniendo en cuenta ambos aspectos: la necesidad y la urgencia. La primera, referida a la producción de conocimiento arqueológico y paisajístico que permita evaluar en qué términos se dio la ocupación persistente en estos espacios complejos. La segunda, la urgencia, relacionada al relevamiento minucioso de información arqueológica que permita evaluar el impacto que tendría la ejecución de dicho emprendimiento sobre el patrimonio cultural.

El objetivo de este trabajo es presentar una caracterización pormenorizada del registro arqueológico de RLS2, a partir de los resultados de la prospección arqueológica intensiva y extensiva. Esto nos permitirá, a su vez, discutir la validez de la metodología empleada y su repercusión en la profundización de la interpretación arqueológica de la cantera-taller RLS2, como espacio multipropósito.

\section{El ambiente natural y cultural: Pavimento, Estabilidad y Registro arqueológico}

El área de estudio se inserta dentro del ambiente morfoestructural de las Sierras Pampeanas, caracterizado en el noroeste tucumano por la presencia de dos cordones montañosos: Sierras del Aconquija y Cumbres Calchaquíes, separados entre sí por una depresión tectónica de rumbo NO-SE que coincide en el SE con el valle de Tafí y en el NO con la quebrada de Amaicha (Mon y Mansilla, 1998) (Figura 1A).

La vertiente occidental de esta divisoria de aguas presenta un paisaje sedimentario complejo, caracterizado por eventuales afloramientos de areniscas de origen Terciario sobre las que se asientan conos de deyección de origen fluvial, gravas de gran porte y depósitos. Estos últimos resultan de movimientos en masa vinculados a deslizamientos poco profundos, flujos y avalanchas de detritos, asociados a pedimentos (glacis) de pendiente suave (Strecker et al., 1989). Estos glacis se encuentran cubiertos por una delgada cobertura detrítica constituida por rocas del basamento cristalino y vulcanitas (Durando et al. 1986). La distribución espacial de este complejo paisaje se halla controlada por las precipitaciones (como factor desencadenante), por la orientación y grado de inclinación de las pendientes, su litología (o grado de meteorización 

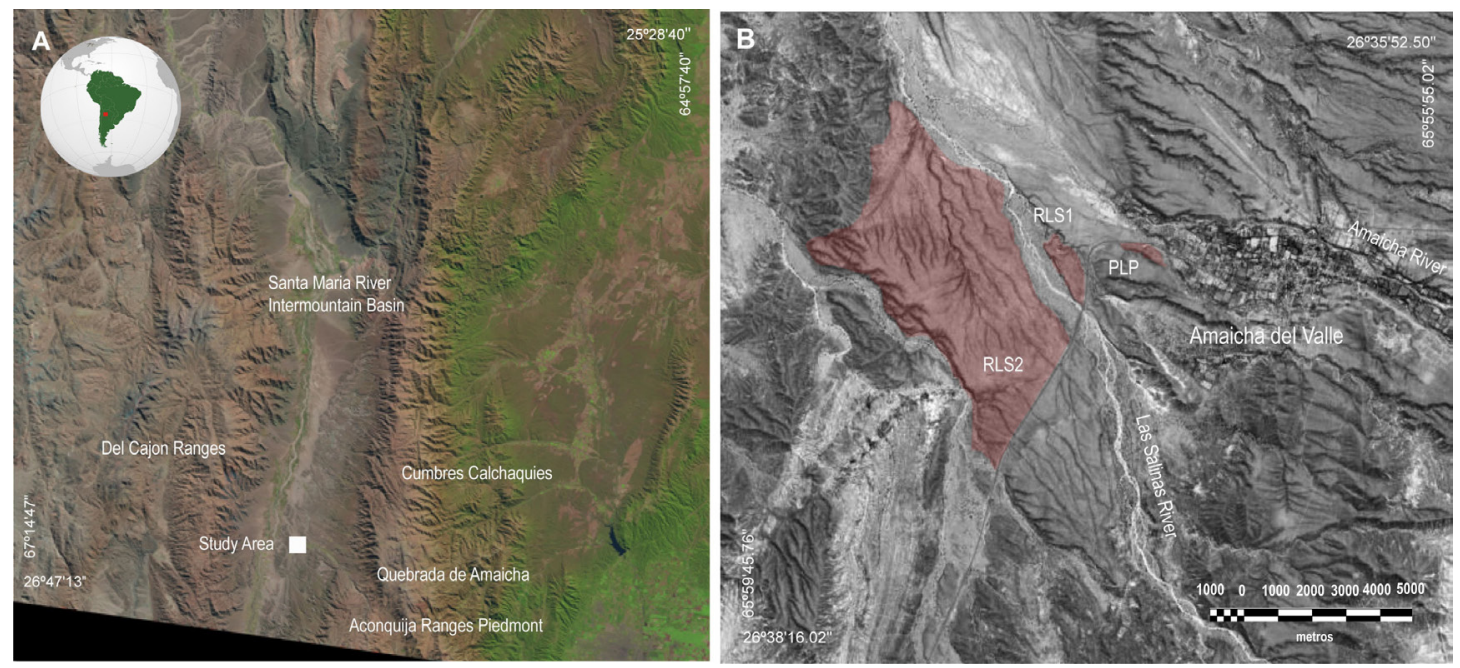

Figura 1 A y B. Localización del área de estudio (A) y de las superficies de glacis mencionadas en el texto (B).

Figure 1 A and B. Location of the study area (A) and of the glacis surfaces mentioned in the text $(B)$. de los materiales que conforman las distintas geoformas), y por procesos erosivos de origen antrópico (vinculados al uso del suelo) y naturales (vinculados al escurrimiento superficial, vientos y bioturbación primordialmente) (Collantes y González, 2012).

El clima es del tipo desértico frío, de carácter monzónico con precipitación pluvial que rara vez supera los $200 \mathrm{~mm}$ anuales, concentrada durante los meses de noviembre a marzo (Sesma et al., 1998). En el área pueden encontrarse especies arbóreas, como algarrobos (Prosopis alba y Prosopis nigra), churquis (Acacia caven), arcas (Acacia visco), chañares (Geoffroea decorticans); breas (Cercidium praecox); arbustos como Bulnesia sp.; Monthea aphylla, jarillales de Larrea cuneifolia y Larrea divaricata; cactáceas como cardones (Trichocereus atacamensis y Opuntia sulphuria) y, especies de zonas inundadas o ribereñas, como pajonales formados por totoras (Typha latifolia) y juncales (Juncus sp.) (Collantes y González, 2012).

RLS2 forma parte de una superficie de glacis mayor que se encuentra disectada, hacia el noreste, por el cauce y llanura de inundación del río Las Salinas, en un sector medio por la Ruta Provincial n³57 y, hacia el suroeste, por el río La Paloma (Figura 1B). Sobre la superficie de RLS2 se desarrollan pavimentos (o pedregosidad), uno de los procesos geomorfológicos comunes del área. En general los pavimentos son vistos como espacios apropiados arqueológicamente para el abordaje de la estabilidad de los conjuntos artefactuales, en el largo plazo (Aldersberger y Smith, 2009; Aldersberger et al., 2013 Barton, 2003; Matmon et al., 2009). Por definición, están caracterizados por una capa superficial de clastos gruesos que recubren sedimentos finos (Aldersberger y Smith, 2009). En Amaicha del Valle, la cobertura de estos pavimentos consiste en clastos volcánicos angulares y subredondeados, fundamentalmente de andesitas y basaltos $y$, en menor proporción, cuarzos y rocas metamórficas que recubren un sedimento, principalmente arenoso y de diferentes granulometrías. Estos pavimentos ocupan la división topográfica generada por canales por donde circula el agua en la época estival, en sentido SENO y que disectan internamente el paisaje. A pesar de la estabilidad asociada a los pavimentos, las superficies de los mismos no son estáticas y están sujetas a distintas condiciones tafonómicas. Esto se traduce en que dicho pavimento posee grados variables de preservación y madurez (inferida a partir del tamaño de los clastos) y está afectado por bioturbación, cobertura vegetal, erosión hídrica y eólica (deflación). Estas variantes en la estabilidad se ven claramente reflejadas en el paisaje. En las áreas menos estables, donde los tamaños de los clastos son menores en tamaño y densidad, la preservación del pavimento se encuentra comprometida, es decir, manifiesta cierta madurez y, por lo tanto, cierto grado de deterioro (Somonte y Baied, 2017). Asimismo, en las áreas más estables, en las que los tamaños de los clastos son más importantes y densos, es donde el pavimento cuenta con cierto grado de preservación. Los pavimentos mejor preservados son los que poseen la mayor concentración y densidad de artefactos líticos. En estos casos, la presencia de barniz de las rocas asociado a los artefactos, sumada a los eventos de talla in situ son indicadores de que la superficie de glacis sobre las que yacen los conjuntos líticos es una geoforma relativamente estable (Somonte y Baied, 2017). Esto es esperable en pavimentos maduros, entendidos como superficies de larga vida (Aldersberger et al., 2013; Matmon et al., 2009).

La antigüedad del barniz de las rocas en el área de valles y quebradas del NOA pudo determinarse mediante la técnica de datación correlativa, VML (varnish microlamination), desarrollada por Tanzhuo Liu (Dorn, 2004, 2007, 2009; Liu, 2003; Liu y Dorn, 1996; Liu y Broecker, 2000, 2007, 2008a, 2008b). Hasta el momento se han obtenido un total de 19 fechados sobre el barniz que recubre negativos de lascado de artefactos líticos y sobre el barniz que afecta a la corteza de las rocas (Tabla 1). Nueve dataciones de VML procedentes de Planchada La Puntilla (PLP) permitieron establecer que el uso de este espacio habría comenzado, al menos, hace 
Tabla 1. Dataciones tempranas en valles intermontanos del noa. ${ }^{*}$ Este fechado está expresado en años ${ }^{14} \mathrm{C}$ ap.

Table 1. Early dating in intermontane valleys of the noa. ${ }^{*}$ This dating is expressed in $14 c$ bp years.

\begin{tabular}{|c|c|c|c|c|c|}
\hline PROCEDENCIA & MUESTRA & MATERIAL & FECHADO & EDAD calibrada & FUENTE \\
\hline Rio Las Salinas 2 & $712-1 \mathrm{~A}$ & Lítico/Negativo de lascado & VML & 14150 años AP & Somonte y Baied 2018 \\
\hline Rio Las Salinas 2 & $712-1 \mathrm{~B}$ & Lítico/Negativo de lascado & VML & 13150 años AP & Somonte y Baied 2018 \\
\hline Rio Las Salinas 2 & $712-1 C$ & Lítico /Negativo de lascado & VML & 12350 años AP & Somonte y Baied 2018 \\
\hline Rio Las Salinas 2 & $712-1 D$ & Lítico/Negativo de lascado & VML & 12350 años AP & Somonte y Baied 2018 \\
\hline Rio Las Salinas 2 & $709-2 A$ & Lítico /Negativo de lascado & VML & 9400-10300 años AP & Somonte y Baied 2018 \\
\hline Rio Las Salinas 2 & $709-2 B$ & Lítico/Negativo de lascado & VML & 9400 años AP & Somonte y Baied 2018 \\
\hline Ampajango & D11-A & Lítico/Negativo de lascado & VML & 9400 años AP & Carbonelli 2014 \\
\hline Ampajango & D11-B & Lítico/Negativo de lascado & VML & 8100 años AP & Carbonelli 2014 \\
\hline Ampajango & $\mathrm{C} 10-\mathrm{C}$ & Lítico/Negativo de lascado & VML & 8100 años AP & Carbonelli 2014 \\
\hline Ampajango & C10-D & Lítico/Negativo de lascado & VML & 8100años AP & Carbonelli 2014 \\
\hline Planchada La Puntilla & ARG-201-A & Lítico/Negativo de lascado & VML & 5900 años AP & Somonte y Baied 2011; 2013 \\
\hline Planchada La Puntilla & ARG-201-B & Lítico/Negativo de lascado & VML & 5900 años AP & Somonte y Baied 2011; 2013 \\
\hline Planchada La Puntilla & ARG-201-C & Lítico/Negativo de lascado & VML & 5900-6500 años AP & Somonte y Baied 2011; 2013 \\
\hline Planchada La Puntilla & ARG-201-D & Lítico/Negativo de lascado & VML & 5900 años AP & Somonte y Baied 2011; 2013 \\
\hline Planchada La Puntilla & ARG-201-E & Litico/Corteza & VML & 5900 años AP & Somonte y Baied 2011; 2013 \\
\hline Planchada La Puntilla & ARG-201-F & Lítico/Corteza & VML & $6500-7300$ años AP & Somonte y Baied 2011; 2013 \\
\hline Planchada La Puntilla & ARG-201-G & Lítico/Corteza & VML & 5900 años $A P$ & Somonte y Baied 2011; 2013 \\
\hline Planchada La Puntilla & ARG-201-H & Lítico/Corteza & VML & $5900-6500$ años AP & Somonte y Baied 2011; 2013 \\
\hline Planchada La Puntilla & ARG-201-I & Lítico/Corteza & VML & $5900-6500$ años $A P$ & Somonte y Baied 2011; 2013 \\
\hline Taller Puesto Viejo 1 & UGAMS-9096 & Óseo & Radiocarbono & $7420 \pm 25$ años $A P^{*}$ & Martinez et al. 2013 \\
\hline
\end{tabular}

6500-5900 años AP y continuó hasta momentos tardíos (para más detalle ver Somonte y Baied, 2013; Somonte y Baied, 2011). Otros seis fechados obtenidos para RLS2 profundizan la temporalidad en el uso de estos espacios, ya que abarcan un rango temporal que va de 13.150 a 9400 años AP (Somonte y Baied, 2018). Estas dataciones tempranas no constituyen un evento aislado en Amaicha del Valle, sino que se suman a fechados tempranos en otros sitios de los valles intermontanos del NOA que, en conjunto, conforman las evidencias más tempranas de ocupaciones cazadoras para los valles. Nos referimos a las cuatro dataciones de VML entre 9400-8100 años AP para la cantera de Ampajango (Carbonelli, 2014) y al fechado radiocarbónico de $7420 \pm 25$ años AP para el sitio Taller Puesto Viejo 1 en la quebrada de Los Corrales (Martínez et al., 2013) (Tabla 1).

\section{Metodología}

La prospección arqueológica reúne un conjunto de técnicas destinadas a la obtención de información apropiada para estimar diversos parámetros o características del registro arqueológico regional (Dunnell y Dancey, 1983; Schiffer et al., 1978). Este registro fue definido, por los autores, como una distribución más o menos continua de artefactos sobre la superficie con características de densidad altamente variables (op.cit). Paralelamente, los procesos medioambientales involucrados en la formación del registro arqueológico regional deben ser considerados tanto en el diseño de prospección, como así también al momento de hacer inferencias basadas en los datos procedentes de la prospección (Schiffer, 1987). Entre los factores que influyen en la probabilidad de descubrimiento se encuentran las características de los materiales arqueológicos, las propiedades climáticas y geológicas del ambiente del área de estudio y otros factores que dependen de los arqueólogos, como las técnicas y estrategias de prospección (Banning, 2002; Banning et al., 2006; Schiffer et al., 1978; Wandsnider y Camilli, 1992, entre otros).
La prospección se realizó en el mes de julio, tuvo 8 días de duración con jornadas de 8 hs. de trabajo de campo. Consistió en la cobertura total de la superficie de RLS2, a través de un diseño que contempló factores como visibilidad, accesibilidad y obstrusividad (sensu Schiffer, 1987), ya que junto a las técnicas de prospección, influyeron en qué es lo que se encontró en esta intervención arqueológica. La técnica básica fue la táctica pedestre, definida como la inspección sistemática de la superficie de una unidad de prospección por un equipo de observadores, espaciados en intervalos regulares (Schiffer et al., 1978). La unidad de prospección fue la totalidad de la superficie de RLS2, es decir las 620 has. Esta prospección estuvo organizada a través del trazado de 560 transectas paralelas, en sentido E-O, de $10 \mathrm{~m}$ de ancho cada una y una longitud variable que estuvo entre 0,60 y 2,5 km, dependiendo de la extensión del glacis en sí mismo. Estas transectas fueron recorridas de forma pedestre por ocho personas, repartidas en grupos de dos individuos por cada transecta; durante dicho recorrido, se describieron elementos arqueológicos en relación con el entorno paisajístico inmediato. Para tal fin, se diseñaron cuatro tipos de fichas (tres arqueológicas y una paisajística/ambiental) que fueron utilizadas durante la prospección y en las que quedó consignada la información recolectada. De esta manera, en cada lugar donde se tomó un punto con GPS, se completó ya sea una ficha del paisaje/ambiente y otra del tipo de hallazgo arqueológico encontrado en ese espacio (arte rupestre, concentración de material lítico y/o estructura arquitectónica), o se utilizaron varias fichas según la combinación de hallazgos registrados en ese mismo lugar. La información de la ficha paisajística/ambiental estuvo relacionada con una descripción geológica y geomorfológica general del espacio físico circundante e inmediato al hallazgo arqueológico, incluyendo aspectos críticos que hacen a las características de los sedimentos, la vegetación, los procesos de formación de sitio naturales y culturales, incluyendo propiedades de los pavimentos. Esto permitió evaluar, posteriormente, aspectos de visibilidad, 
accesibilidad y obstrusividad de artefactos y distribuciones mayores de artefactos (en sentido amplio). Las fichas arqueológicas consignaron, por separado, atributos de cada uno de los tipos de evidencia arqueológica ya conocida y representativa del registro arqueológico en RLS2. Dentro de cada ficha se incorporaron las fotografías de los hallazgos registrados, así como los croquis (cuando la situación lo requirió), que complementaron el registro de la totalidad de los hallazgos detectados durante la prospección. La ficha de arte rupestre incluyó una descripción de los motivos representados, la modalidad técnica, las dimensiones del soporte, la presencia de pátinas, grado de patinación de los motivos, entre otras. La ficha de estructura arquitectónica contempló la morfología, el tipo de asociación, las dimensiones, características de las técnicas constructivas, entre otras. La ficha de concentración de materiales líticos incluyó clases tipológicas presentes, materia prima, dimensiones/ extensión, posibilidades de ensamblaje, pátinas asociadas, etc. En el campo se identificaron, de manera preliminar, los grupos tipológicos de los artefactos formatizados, así como también, los tipos de lascas y la designación morfológica de los núcleos. Si bien la prospección no incluyó la recolección de material arqueológico, se realizó una recolección superficial de ciertos artefactos líticos, relevantes para la Arqueología del área desde un punto de vista tecnológico. Los resultados del análisis tecnomorfológico y morfológico funcional de estos materiales no forman parte de este trabajo.

Las categorías definidas para los hallazgos incluyeron objetos individuales, así como conjuntos de objetos. Es decir, algunas categorías contienen concentraciones de materiales arqueológicos (como, por ejemplo, los materiales líticos), mientras que otras categorías aluden a la presencia de un único (en sentido numérico) elemento arqueológico (como ser un soporte con arte rupestre o un artefacto aislado). Esto es importante a la hora de entender qué están representando los puntos de GPS relevados durante la prospección, aspecto que será retomado en la discusión.

\section{Resultados}

Los hallazgos relevados en RLS2 durante la prospección fueron altamente sensibles mediante la táctica pedestre, debido a la naturaleza superficial de los materiales arqueológicos. Además, esto tuvo relación con el hecho de haber ido al campo en invierno, estación seca para el área, donde la escasa vegetación, estuvo aún más reducida desde el punto de vista de su follaje, permitiendo una mayor visibilidad durante el recorrido de las transectas. La accesibilidad se vio dificultada por la presencia de cárcavas y la concentración de vegetación (sobre todo arbustiva y, en menor medida, arbórea) asociada a esas cárcavas, que nos forzaron a desviar levemente el trazado lineal del recorrido de las transectas en esos sectores puntuales.
RLS2 se encuentra afectado, fundamentalmente, por procesos erosivos hídricos y eólicos; en segunda medida por bioturbación (cuevas de roedores y pisoteo de animales) y, finalmente, procesos tales como el tránsito actual de personas y animales que se ve reflejado en caminos vecinales, sendas activas y sendas sumamente desdibujadas (hasta perderse en el terreno) debido al desuso. A esto se suma el uso de espacios puntuales como basureros.

El sedimento que forma la matriz de RLS2 está constituido, mayoritariamente, por arenas de diferentes granulometrías y por una pequeñísima fracción de limo y arcilla. El viento ha ejercido su acción erosiva, fundamentalmente, mediante la deflación, mecanismo que influye, junto con otros procesos, en la formación de los pavimentos.

El escurrimiento del agua en RLS2 se da en sentido N-S, siguiendo la dirección predominante de la pendiente (entre $1^{\circ}$ y $5^{\circ}$ ), y su consecuencia sobre el paisaje se relaciona con la topografía local. Se observaron distintos efectos de la erosión hídrica, como ser el efecto por gotas de lluvia, erosión laminar, erosión en surcos y cárcavas. En la actualidad, los canales más profundos de escorrentía del agua cuentan con vegetación arbustiva e, inclusive, cactácea y arbórea.

Los puntos relevados con GPS suman un total de 420 y corresponden a las distribuciones de hallazgos detectados en el área prospectada (Figura 2). Todos los hallazgos fueron agrupados en 8 categorías, incluyendo la combinación de algunas de ellas: 1) concentración de materiales líticos ( $n=162) ; 2$ ) estructuras arquitectónicas $(n=133) ; 3)$ artefactos aislados $(n=58) ; 4)$ soportes con arte rupestre $(n=38) ; 5)$ estructuras arquitectónicas y concentración de materiales líticos $(n=18) ; 6)$ estructuras arquitectónicas y arte rupestre $(n=8)$; 7$)$ concentración de materiales líticos y arte rupestre $(n=2)$ y 8$)$ estructuras arquitectónicas, concentración de materiales líticos y arte rupestre $(n=1)$ (Tabla 2$)$.

La distribución de los hallazgos que se muestra en la Figura 2 da cuenta de la existencia de materiales arqueológicos en gran parte del área prospectada. También se registraron lugares puntuales degradados, donde es notoria la disminución en las densidades de dichas distribuciones. Al respecto, hacia el oeste del área prospectada se registra una marcada disminución de puntos de interés arqueológico, así como en el sector norte, donde se aprecia un área donde están prácticamente ausentes los materiales arqueológicos con excepción de dos soportes con arte rupestre. Esta zona se correlaciona con un espacio sumamente degradado y erosionado, afectado principalmente por la acción de la escorrentía, donde predomina un arenal de gran extensión (Figura 3). 


\begin{tabular}{|c|c|}
\hline Categorías & Subtotal (n) \\
\hline Estructuras arquitectónicas & 133 \\
\hline Concentración de materiales líticos & 162 \\
\hline Soportes con Arte rupestre & 38 \\
\hline $\begin{array}{c}\text { Estructuras arquitectónicas y } \\
\text { concentración de materiales líticos }\end{array}$ & 18 \\
\hline $\begin{array}{c}\text { Estructuras arquitectónicas y arte } \\
\text { rupestre }\end{array}$ & 8 \\
\hline $\begin{array}{c}\text { Concentración de materiales líticos y Arte } \\
\text { rupestre }\end{array}$ & 2 \\
\hline $\begin{array}{c}\text { Estructuras arquitectónicas, } \\
\text { Concentración de materiales líticos y Arte } \\
\text { rupestre }\end{array}$ & 1 \\
\hline Artefactos aislados & 58 \\
\hline Total (N) & 420 \\
\hline
\end{tabular}

Tabla 2. Categorías de hallazgos arqueológicos en RLS2.

Table 2. Categories of archaeological finds in RLS2.

Fligura 2. Distribución de los hallazgos arqueológicos relevados con GPS en RLS2.

Figure 2. Distribution of the archaeological finds surveyed with GPS in RLS2.

\begin{tabular}{|c|l|}
\hline Referencias/ References \\
\hline $\mathbf{O}$ & $\begin{array}{l}\text { Concentración de material litico } \\
\text { Concentration of lithic material }\end{array}$ \\
\hline $\mathbf{D}$ & $\begin{array}{l}\text { Estructuras arquitectónicas } \\
\text { Architectural features }\end{array}$ \\
\hline $\mathbf{D}$ & $\begin{array}{l}\text { Artefactos aislados } \\
\text { Isolated artifacts }\end{array}$ \\
\hline $\mathbf{O}$ & $\begin{array}{l}\text { Arte rupestre; Arte rupestre y estructuras arquitectónicas; Arte rupestre y concentración de material litico; Arte } \\
\text { rupestre, estructuras arquitectónicas y concentración de material litico } \\
\text { Rock art, Rock art and Architectural features, Rock art and Concentration of lithic material, Rock art, } \\
\text { Architectural feautures and Concentration of lithic material }\end{array}$ \\
\hline $\mathbf{O}$ & $\begin{array}{l}\text { Estructuras arquitectónicas y concentración de material litico } \\
\text { Architectural features and Concentration of lithic material }\end{array}$ \\
\hline
\end{tabular}

Los recursos líticos disponibles en RLS2 fueron utilizados como materia prima para la manufactura de artefactos líticos, como soporte del arte rupestre y para la construcción de distintos tipos de estructuras arquitectónicas (recintos, alineamientos y otras). Rocas como basaltos y andesitas se encuentran altamente disponibles en RLS2 y distribuidas de manera concentrada sobre la superficie de este glacis. Los clastos se encuentran, en base a la escala granulométrica de Udden-Wentworth, bajo la forma de bloques que superan ampliamente los 25,6 cm de eje máximo y varían su tamaño hasta llegar a $80 \mathrm{~cm}$. También se presentan como rodados con dimensiones variables, guijones (eje mayor entre 6,4 y 25,6 cm), guijarros (eje mayor entre 1,6 y $6,4 \mathrm{~cm}$ ) y guijas (eje mayor entre 0,4 y 1,6 cm). Entre los rodados se registraron algunos redondeados y otros aplanados, éstos últimos considerados como nódulos tabulares (Aschero, 1975).

La variabilidad en el tamaño, peso y forma de caja de los recursos líticos tiene un correlato con el tipo de materialidad arqueológica. Los de mayor tamaño han sido utilizados para la construcción de estructuras, como soportes para el arte rupestre y cómo nódulos para la extracción de grandes lascas.

Por otro lado, las andesitas y basaltos también están disponibles en RLS2, bajo la forma de materiales líticos tallados que se encuentran en distintas etapas de producción y distribuidos en forma concentrada en determinados sectores o áreas de explotación y producción lítica. En este sentido, las concentraciones de materiales líticos cuentan con una amplia distribución sobre la superficie de RLS2 (Figura 2) y si bien su mayoría son de andesitas y basaltos, también los hay de otros recursos utilizables, aunque en menor proporción (cuarzo). Además, se registraron entre las materias primas, rocas silíceas, no disponibles en el ámbito de RLS2, pero sí a lo largo de la quebrada del río Amaicha.

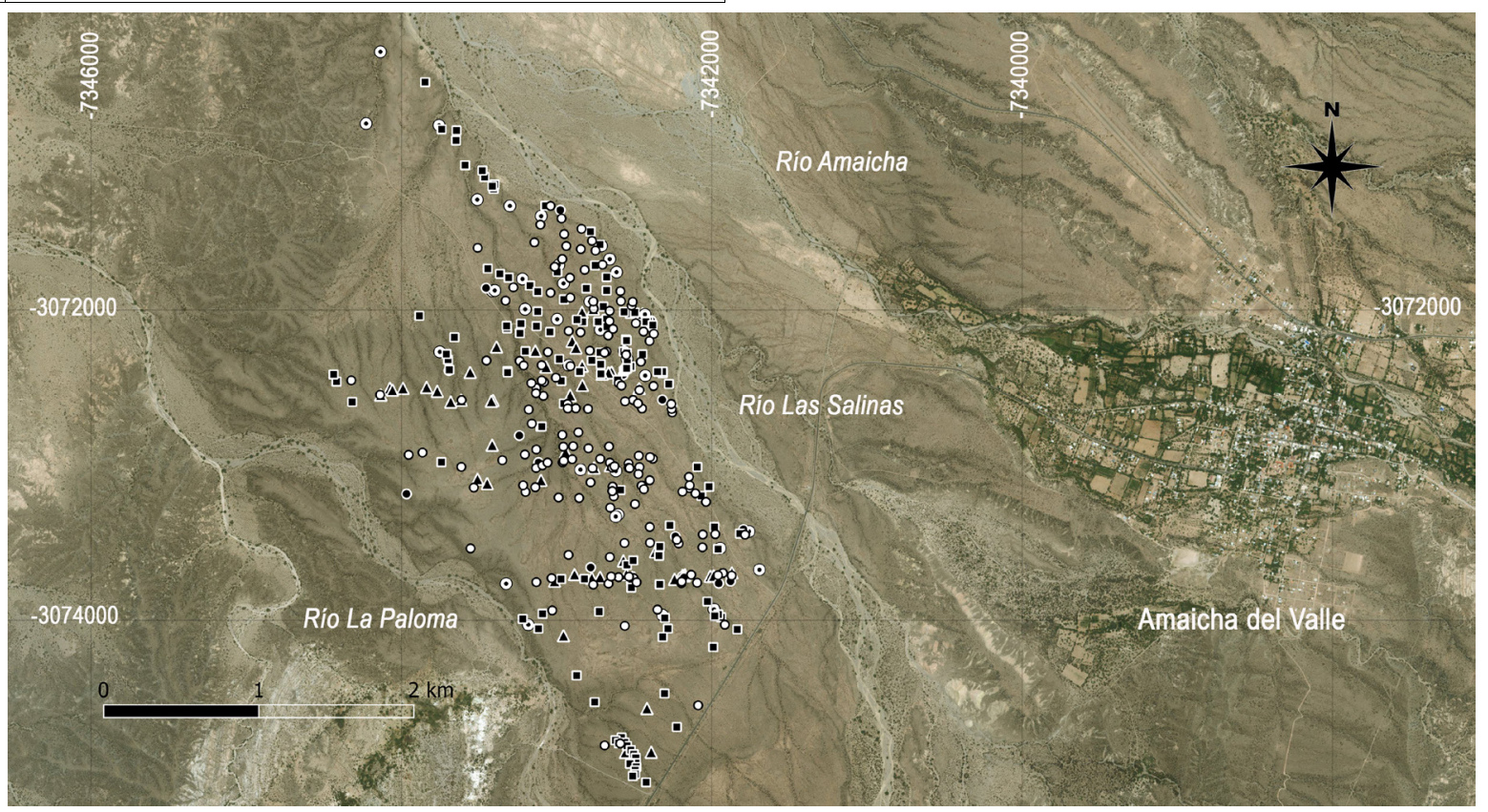



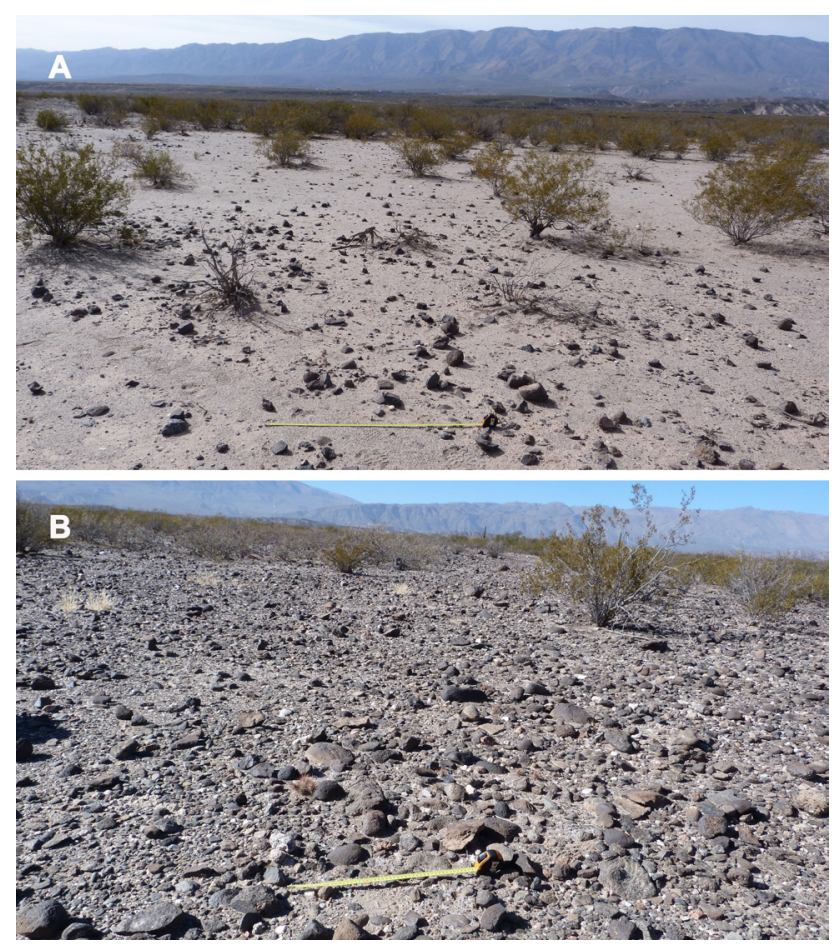

Figura 3. Paisajes contrastantes: A. Degradado con ausencia de materiales arqueológicos; B. Conservado, pavimento asociado a materiales arqueológicos.

Figure 3. Contrasting landscapes: $A$. Degraded with absence of archaeological materials; $B$. Preserved, pavement associated with archaeological materials.

Los conjuntos líticos mencionados fueron tallados in situ y su depositación cultural refleja, en cierto sentido, una situación de abandono o descarte. Estos artefactos, además, poseen evidencia de haber sido reclamados o retomados, es decir, que constituyen talleres que, a su vez, conforman una cantera para el aprovisionamiento, asociados a la fuente secundaria que los contiene. Debe señalarse que el carácter secundario de los nódulos redondeados y tabulares de la fuente no incluye a estos materiales líticos tallados (Somonte y Baied, 2011).

Por otra parte, dentro de la categoría de concentración de materiales líticos, existe cierta variabilidad, basada en la extensión de estos ámbitos productivos. Por un lado, se registraron espacios cuyas dimensiones varían entre dos y $250 \mathrm{~m}^{2}$ de extensión $(\mathrm{n}=135)$. Entre las clases tipológicas presentes en estas concentraciones de materiales líticos se destacan núcleos, lascas corticales e internas diversas, filos naturales con rastros complementarios y artefactos bifaciales y unifaciales (con distintos grados de formatización y estados de fragmentación).

Los grupos tipológicos registrados durante la prospección en RLS2 son similares a los ya conocidos para el área, donde predominan cuchillos, muescas, raederas y denticulados, cuyos filos fueron formatizados mediante retoque marginal y talla marginal (Somonte y Baied, 2018). Entre los artefactos bifaciales se encuentran bifaces, esbozos de piezas bifaciales y fragmentos de filo bifacial de arista sinuosa. En algunos de los filos unifaciales y bifaciales se observaron, bajo microscopio metalográfico, rastros complementarios de uso (Germano, 2016).

Por otro lado, se registraron concentraciones menores de materiales líticos tallados, cuya extensión y densidad son más reducidas que las anteriores, ya que no superan el metro cuadrado $(n=27)$. Se trata de concentraciones compuestas por núcleos, lascas y, excepcionalmente, algún artefacto formatizado, donde las clases tipológicas comparten la misma materia prima.

Hemos observado que algunos de los componentes líticos de estos espacios, independientemente de su extensión, ofrecen la posibilidad de ensamblaje (sensu Ramos, 1993). Estos conjuntos líticos son entendidos en este trabajo como los correlatos materiales de eventos de talla (sensu Blanco et al., 2010). Este aspecto es algo común en aquellos sectores de RLS2 donde los pavimentos manifiestan cierta preservación, tema que ya fue tratado en trabajos anteriores (Somonte y Baied, 2013; 2017).

En cuanto a las estructuras arquitectónicas, se destacan las de forma circular y semicircular (o en forma de herradura o " $U$ "; $n=75)$, lineal $(n=29)$, monticular $(n=26)$ y subcuadrangular $(n=3)$. Con respecto a la asociación de las estructuras arquitectónicas entre sí, notamos que en su mayoría se trata de estructuras simples, aisladas y separadas, es decir que no hay aglutinación de las mismas.

Las estructuras de forma circular poseen dimensiones variables entre 0,60 y $5 \mathrm{~m}$ de diámetro; las semicirculares entre 0,50 y 2,50 m de diámetro; las lineales poseen entre uno y $40 \mathrm{~m}$ de longitud y, finalmente, las monticulares entre 1 y $5 \mathrm{~m}$ de diámetro. La altura de los muros de estas estructuras se encuentra al ras del suelo, sólo algunas de las monticulares alcanzan 0,80 m (Tabla 3 y Figura 4). En todos los casos, las construcciones fueron realizadas con rocas sin cantear y sin argamasa, de tipo andesíticas, basálticas y metamórficas, altamente disponibles en la superficie del glacis. Éstas no evidencian tareas de mantenimiento, reparación, modificación arquitectónica alguna.

Las estructuras circulares y semicirculares predominan en RLS2, ya que suman cerca del $57 \%$ del total de estructuras (Figura 4 A, C y E). Aunque en su mayoría son simples y están aisladas, también hemos notado algunos casos en los que se disponen de a pares, separadas por dos o tres metros entre sí. Si bien sus construcciones son de muros simples, se registró un solo caso de un recinto circular con muro doble (Figura $4 \mathrm{D}$ ). Entre las estructuras de forma circular, las compuestas, representan una minoría que no supera el 2\%. En el caso de aquellas estructuras arquitectónicas cuyos diámetros son inferiores a un metro, hemos detectado que las mismas poseen una roca de gran tamaño en el centro, que ocupa casi el diámetro 


\begin{tabular}{|c|c|c|c|c|c|}
\hline $\begin{array}{l}\text { Forma estructura } \\
\text { arquitectónica }\end{array}$ & Dimensiones & Altura & Tipo de asociación & $\begin{array}{l}\text { Distancia entre } \\
\text { estructuras }\end{array}$ & Materialidad asociada \\
\hline $\begin{array}{l}\text { Semicircular o en } \\
\text { forma de " } U \text { " }\end{array}$ & Entre 0,50 y $2,50 \mathrm{~m}$ & Entre 0,20 y $0,40 \mathrm{~m}$ & $\begin{array}{c}\text { Simples o dispuestas de a } \\
\text { dos }\end{array}$ & Entre 2 y $3 \mathrm{~m}$ & $\begin{array}{l}\text { Concentración de } \\
\text { material lítico } \\
\text { Arte rupestre }\end{array}$ \\
\hline Circular & Entre 0,60 y $5 \mathrm{~m}$ & Entre 0,20 y $0,50 \mathrm{~m}$ & $\begin{array}{c}\text { Simples o dispuestas de a } \\
\text { dos. }\end{array}$ & Entre 2 y $3 \mathrm{~m}$ & $\begin{array}{c}\text { Concentración de } \\
\text { material lítico } \\
\text { Arte rupestre } \\
\text { Otras estructuras }\end{array}$ \\
\hline Lineal & Entre 1 y $40 \mathrm{~m}$ & Alrededor de $0,30 \mathrm{~m}$ & Simples & - & $\begin{array}{l}\text { Concentración de } \\
\text { material lítico } \\
\text { Arte rupestre } \\
\text { Otras estructuras }\end{array}$ \\
\hline $\begin{array}{c}\text { Monticular } \\
\text { Acumulación } \\
\text { menor de piedras }\end{array}$ & $\begin{array}{l}\text { Entre } 4 \text { y } 1 \mathrm{~m} \\
\text { Entre } 0,50 \text { y } 1 \mathrm{~m}\end{array}$ & $\begin{array}{l}\text { Entre } 0,60 \text { y } 0,80 \mathrm{~m} \\
\text { Entre } 0,30 \text { y } 0,50 \mathrm{~m}\end{array}$ & Simples & Entre 1 y $1,50 \mathrm{~m}$ & $\begin{array}{l}\text { Otras estructuras } \\
\text { Arte rupestre } \\
\text { Concentración de } \\
\text { material lítico }\end{array}$ \\
\hline Subcuadrangular & $\begin{array}{c}\text { Entre } 0,70 \text { y } 1 \mathrm{~m} y \\
1,70 \times 1,90 \mathrm{~m}\end{array}$ & Entre 0,50 y $0,80 \mathrm{~m}$ & Simples & - & $\begin{array}{l}\text { Concentración de } \\
\text { material lítico }\end{array}$ \\
\hline
\end{tabular}

Tabla 3. Caracterización de las estructuras a rquitectónicas registradas en RLS2.

Table 3. Characterization of the architectural structures recorded at RLS2.

de la misma estructura (Figura 4 B). Este es un patrón común entre las estructuras arquitectónicas circulares y semicirculares que poseen diámetros reducidos.

Por su parte, entre las estructuras lineales, en su mayoría se tratan de alineaciones simples, de longitudes variables, entre 1 y 40 m, cuya disposición no guarda una relación particular respecto a la pendiente, ni se orientan en sentido perpendicular a la misma (Figura 4 F). Estas se encuentran relacionadas a otro tipo de estructura arquitectónica, circular o semicircular, o bien a soportes con arte rupestre. En general, manifiestan un bajo grado de preservación, lo que dificulta su clara delimitación y seguimiento en el terreno.

Por otro lado, las estructuras monticulares, cuentan con cierta variabilidad en lo que a tamaño se refiere. Se registraron algunos de dimensiones que alcanzan los $4 \mathrm{~m}$ de diámetro y $0.80 \mathrm{~m}$ de altura, y también, se detectaron otros de menores dimensiones, entre 0,40 y $1 \mathrm{~m}$ de diámetro. A estos últimos los consideramos como "acumulaciones menores de rocas". Esta distinción fue realizada sobre la base del tamaño y con fines meramente prácticos durante los trabajos de campo y no aluden a un aspecto funcional (Tabla 3 y Figura 4 G). Los montículos y las acumulaciones menores de rocas, incluyen depósitos (pilas) de rocas o clastos seleccionados de dimensiones mayores a los 0,10 m. En general, se encuentran aisladas, pero en vinculación con otra clase estructuras arquitectónicas (ya sean circulares, semicirculares y lineales) y, también, con soportes con arte rupestre.

Finalmente, las estructuras subcuadrangulares están reducidas a una mínima expresión en el espacio ( $<2 \%)$. En general, se aprecia una variación en sus dimensiones, los muros de estas estructuras arquitectónicas son simples y la altura de los muros es mayor, con respecto a las circulares y semicirculares (Tabla 3). Se encuentran aisladas, o bien asociadas a concentraciones de materiales líticos y el grado de preservación es muy bueno.=

La distribución de las estructuras en RLS2, muestra cierta polarización, es decir una mayor concentración hacia los extremos norte y sur del área que abarca RLS2 (Figura 2). Entre estos sectores, se aprecia una disminución en el número de estructuras arquitectónicas, sin embargo, es donde se da una importante concentración de materiales líticos.

Una cuestión general que afecta a las estructuras arquitectónicas es el grado variable de preservación de las mismas, ya que se han registrado casos donde sus muros están derrumbados. Además, en algunos casos, las estructuras parecerían haber sido parcialmente desmanteladas e, inclusive, algunas manifiestan evidencias de haber sido huaqueadas. Paralelamente, también

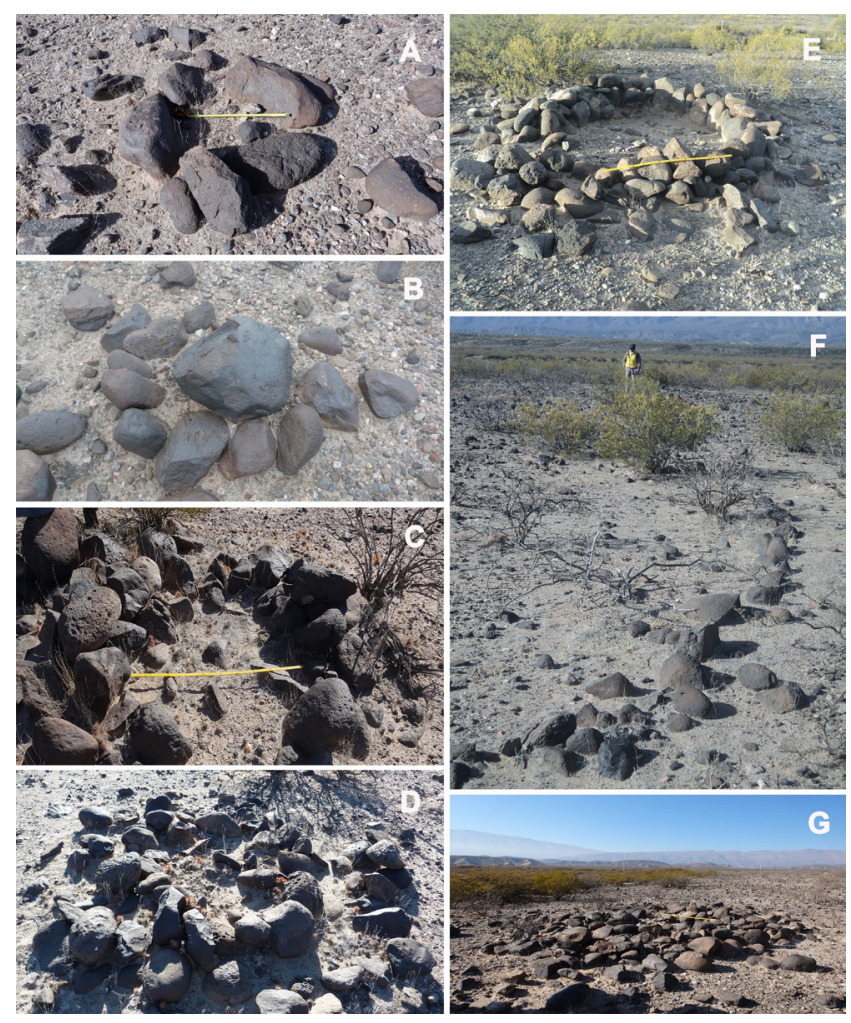

Figura 4. Tipos morfológicos de estructuras arquitectónicas presentes en RLS2. A. Estructura circular. B. Estructura semicircular. C. Estructura semicircular. D. Estructura circular (con muro doble). E. Estructura circular. F. Estructura lineal. G. Estructura monticular.

Figure 4. Morphological types of architectural structures present in RLS2. A. Circular structure. B. Semicircular structure. C. Semicircular structure. D. Circular structure (with double wall). F. Linear structure. G. Monticular structure. 
fueron documentadas estructuras arquitectónicas que cuentan con condiciones excepcionales de preservación. En ese sentido, en RLS2 el avanzado estado de deterioro de numerosas estructuras, ya sea por factores naturales o antrópicos, convive con situaciones en las que se aprecia una muy buena preservación arquitectónica. Al igual que en otros casos, esta preservación diferencial encuentra su correlato con sectores donde el pavimento mismo muestra una integridad variable.

En cuanto al arte rupestre, en general se tratan de grabados realizados bajo la modalidad técnica de picado. Los motivos representados son abstractos, geométricos, zoomorfos y antropomorfos. Entre los abstractos se destacan figuras espiraladas, peiniformes, ovaliformes concéntricas, en forma de $U$, tridígitos y trazos curvilíneos o serpentiformes, entre otros (Figura 5 B, C, D, E, G y $\mathrm{H}$ ). Los motivos zoomorfos más representados son aves (avestruces) y cánidos (zorros) (Figura $5 \mathrm{~A}$ y F). Los soportes con arte rupestre registrados $(n=49)$ poseen dimensiones variables, entre 0,40 y $1 \mathrm{~m}$ y se encuentran distribuidos en puntos específicos del espacio, asociados con estructuras, o bien concentraciones de materiales líticos e, inclusive, con artefactos líticos aislados.

La distribución del arte en el espacio, manifiesta una mayor densidad y concentración de puntos hacia el norte de RLS2, con respecto a otros sectores como por ejemplo el $\mathrm{S}$, donde se aprecia una mayor dispersión y menor densidad de soportes con representaciones rupestres (Figura 2).

Por su parte, entre los artefactos aislados se encuentran instrumentos unifaciales y bifaciales de gran tamaño (superan los $12 \mathrm{~cm}$ ), confeccionados sobre recursos líticos disponibles en la misma superficie de RLS2 (basaltos y andesitas). Entre los filos se destaca la confección de raederas, muescas retocadas, muescas de lascado simple, cuchillos de filo retocado, denticulados, entre otros. Estos tipos de filos están asociados con funciones de corte y raspado, poseen evidencia (rastros y residuos de uso) de haber sido utilizados para la explotación de recursos vegetales y maderables (Germano, 2016; Germano et al., 2019). Se suman a estos artefactos, núcleos prismáticos que denotan la extracción de formas base específicas. También se incluyen muy escasos fragmentos cerámicos decorados, registrados en RLS2, correspondientes estilísticamente a momentos del periodo de Desarrollos Regionales.

Finalmente, en relación al registro arqueológico descripto, un aspecto importante es el barniz de las rocas, fenómeno acrecional datado para el área y de amplia distribución en el NOA. Esta pátina (de color marrón oscuro y brillo metálico) afecta a todo el registro lítico relevado en RLS2, aunque de manera diferencial. Es decir, gran parte de los materiales líticos tallados, las estructuras arquitectónicas y el arte rupestre están afectados por barniz de las

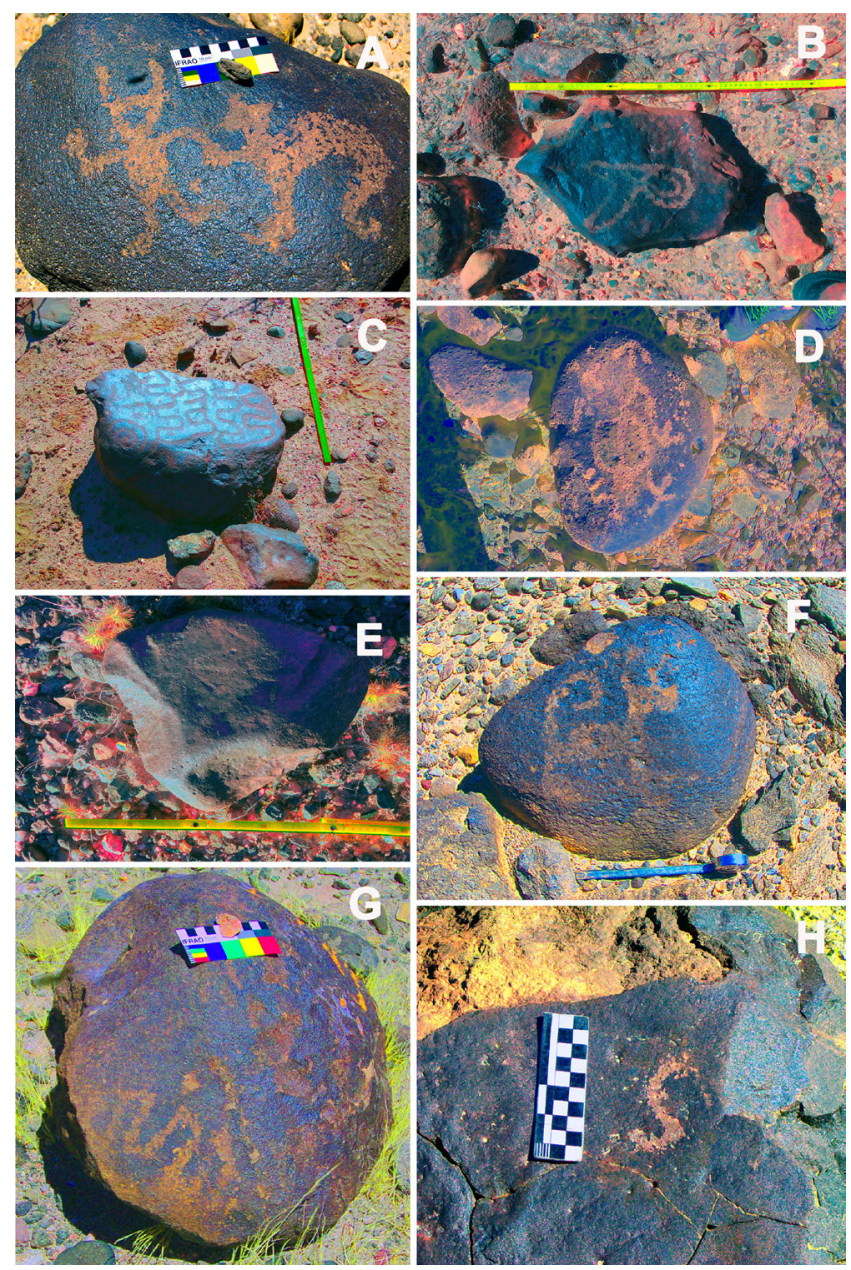

Figura 5. Motivos del arte rupestre presente en RLS2. A. Antropomorfo y zoomoforfo. B. Abstracto. C. Abstracto. D. Abstracto (tridígitos). E. Abstracto (tridígitos). F. Zoomorfo (cánido). G. Abstracto (trazo curvilineo o serpentiforme). H. Abstracto (trazo curvilineo o sepentiforme).

Figure 5. Rock art motifs present at RLS2. A. Anthropomorphic and zoomorphic. B. Abstract. C. Abstract. D. Abstract (tridigits). F. Zoomorphic (canid). G. Abstract (curvilinear or serpentiform). H. Abstract (curvilinear or serpentiform).

rocas, que pueden ser diferenciados por un matiz (intensidad/claridad + croma/pureza) variable. De esta manera los colores Munsell asociados con un desarrollo importante del barniz (relacionados a una mayor antigüedad), corresponden a las tonalidades de marrones oscuros como 5YR2.5/1; 5YR3/1 y 7.5YR3/1. Aquellos componentes del registro lítico que estuvieron sujetos a movimientos, rotaciones o algún otro proceso erosivo (i.e. erosión eólica) que pudieron interrumpir (al resetear) el desarrollo o crecimiento de dicha pátina, presentan colores correspondientes a matices de marrones más claros de la tabla Munsell como, por ejemplo, 7.5YR2/4; 7.5YR3/4; 5YR3/4 o 5YR3/5.

Dentro de las concentraciones de materiales líticos, conviven artefactos sumamente barnizados, con otros menos barnizados e, inclusive, no barnizados, aspecto que marca su producción en diferentes momentos temporales. 
Estas variaciones se aprecian, además, a escala del artefacto, denotando evidencias de reclamación.

Por su parte, la mayoría de las rocas que forman parte de los muros de las estructuras arquitectónicas también están afectadas por barniz de las rocas. En algunos casos, hemos notado que la posición del barniz está acorde a la naturaleza acrecional de formación de esta pátina, es decir que su desarrollo se produjo con posterioridad a la construcción de la estructura arquitectónica. En otros casos, donde se aprecian los muros cuyas rocas poseen el barniz con una disposición invertida (el barniz hacia abajo), es claro que el desarrollo o formación de esta pátina tuvo lugar con anterioridad a la construcción de las estructuras y los constructores utilizaron clastos con el barniz ya formado (o, al menos, iniciado el proceso de desarrollo). Esto da cuenta de que las rocas han sido removidas y desplazadas desde su lugar original de depositación.

En el caso del arte rupestre, el barniz no sólo afecta a los soportes donde está el grabado, sino que también está presente de forma diferencial en la intensidad de sus matices, sobre los mismos grabados, denotando eventos de producción temporalmente variables (Adris, 2013).

\section{Discusión y conclusiones}

Teniendo en cuenta el contexto dual de necesidad y urgencia en el que se produjo esta prospección arqueológica, la discusión girará en torno a: 1) el rol que tuvo el diseño de prospección en cuanto a aspectos cuali-cuantitativos de los resultados obtenidos; 2) la función de RLS2 como cantera-taller y las estrategias de aprovisionamiento lítico y 3) la persistencia en el uso de RLS2 vista desde la arquitectura y el arte rupestre.

\section{El diseño de prospección: aspectos cuali- cuantitativos de los resultados obtenidos}

Los diseños de prospección difieren en muchas características que influyen en los patrones de descubrimiento de los materiales arqueológicos. Una de las variables arqueológicas más significativas de la prospección es la intensidad, entendida como la exhaustividad o grado de detalle con que es recorrida la superficie del área de estudio para encontrar sitios arqueológicos o artefactos (i.e. Ebert et al., 1987; Plog et al., 1978; Schiffer, 1987). En la táctica pedestre, la intensidad es una función directa de la distancia entre operadores, es decir cuanto menos espaciados estén éstos más intensiva será la prospección. En el caso de RLS2, hubo un operador cada $5 \mathrm{~m}$ de distancia, que evitó la duplicación o repetición del registro de materiales arqueológicos localizados sobre el límite de transectas, ya que la cercanía les permitió acordar quien sería responsable de efectuar dicho registro.

Una de las consecuencias de la mayor o menor intensidad con que se lleva adelante una prospección, se refiere al tipo de hallazgo arqueológico que se producirá en uno u otro caso (Banning, 2001; Wandsnider y Camilli, 1992, entre otros). En una prospección poco intensiva, es esperable encontrar sitios con mayor visibilidad (de tamaños importantes); mientras que a través de prospecciones más intensivas se descubrirán sitios de menor visibilidad (menos importantes en cuanto a tamaño). Teniendo en cuenta las categorías de hallazgos para RLS2 (estructuras, concentraciones de material lítico, arte rupestre, artefactos aislados, etc.), la intensidad de la prospección tuvo un impacto directo sobre la escala del tipo de hallazgo arqueológico. A través de estas diferentes categorías se ve reflejada la intensidad de la prospección, dado que las mismas aluden a componentes del registro arqueológico con una visibilidad variable, como son las estructuras arquitectónicas, los soportes con arte rupestre, las concentraciones de materiales líticos y los artefactos aislados.

Por otra parte, la intensidad de una prospección también puede ser evaluada en función de la cantidad de hallazgos en un área o superficie específica. RLS2, con 620 has., contiene un número finito de puntos relevados de distribuciones artefactuales (en sentido amplio), que varían en dimensiones y densidades. En este sentido, los 420 puntos de GPS, en general, no representan un registro del conteo individual del material arqueológico, sino de concentraciones de los mismos. Esto permite sostener que la distribución de puntos que se aprecia en la Figura 2, con excepción de los soportes con arte y los artefactos aislados, se trata de concentraciones artefactuales, incluyendo las estructuras arquitectónicas $y$, en algunos casos, una combinación de hallazgos. La localización de dichas distribuciones depende del grado de preservación de los pavimentos ya que como se expresó, éste repercute de forma directa sobre el registro. La estrecha relación existente entre los pavimentos y el registro arqueológico indica que la discontinuidad o disminución en la densidad de materiales arqueológicos está dada por la misma discontinuidad o interrupción de la superficie con pavimento, es decir la desaparición de dicho fenómeno. La naturaleza superficial del registro arqueológico advierte acerca de su vulnerabilidad a los fenómenos postdepositacionales (principalmente erosivos) que afectan fundamentalmente la superficie de estas geoformas y, por ende, a ciertos fenómenos como los pavimentos. En las superficies altamente erosionadas se registraron, principalmente, estructuras arquitectónicas y soportes con arte rupestre, que corresponden a los hallazgos de mayores dimensiones.

Más allá del caso puntual de RLS2, los pavimentos, como ya expresamos, son un fenómeno característico de este sector de la quebrada de Amaicha, que guardan una directa relación con los glacis. Superficies como Planchada La Puntilla (PLP), Río Las Salinas 1 (RLS1), Campo Grande 1 (CG1) y otros tantos glacis, forman parte del mismo 
fenómeno cuya impronta es la estrecha vinculación entre pavimentos y evidencia arqueológica superficial. Estas superficies contienen un registro arqueológico similar al de RLS2 donde se aprecia un predominio de materiales líticos. Sin embargo, en PLP, RLS1 y CG1 el grado de preservación de los pavimentos es inferior al informado para RLS2, debido a que la neotectónica ha afectado la pendiente de dichas superficies, favoreciendo una mayor intensidad de los procesos erosivos (sobre todo hídricos), que alteraron la estabilidad de esas superficies de glacis $y$, en consecuencia, la preservación de los pavimentos y del registro arqueológico (Hermanns y Strecker, 2001).

Así, los resultados de la prospección extensiva e intensiva sobre 620 has. en RLS2, reafirman una relación existente entre los procesos morfodinámicos y arqueológicos. Se observa que en aquellos lugares donde predomina la degradación paisajística (marcada fundamentalmente por procesos de escurrimiento y, en menor medida, deflación), es bajísima la densidad arqueológica. Inversamente, donde el paisaje se manifiesta menos disturbado y un pavimento preservado, la densidad y variabilidad de los componentes del registro arqueológico adquieren su mayor relevancia. Así, el registro arqueológico existe a un nivel diferente que el de los episodios conductuales que lo produjeron, debido a que es resultado, además, del accionar de los procesos postdepositacionales sobre el mismo (Ebert et al., 1987).

La complejidad de los procesos postdepositacionales que tuvieron, y tienen lugar aún hoy en RLS2, hace que el registro arqueológico no exista bajo la forma de sitios discretos, sino más bien como distribuciones de artefactos y rasgos, de naturaleza más o menos continua sobre la superficie, que son altamente dependientes de las condiciones topográficas locales.

\section{RLS2 como cantera-taller: acerca de las estrategias de aprovisionamiento lítico}

RLS2 forma parte de uno de los ámbitos de aprovisionamiento de recursos líticos de la quebrada de Amaicha, en cuya superficie se encuentran altamente disponibles rocas aptas para la talla, como basaltos y andesitas y, en menor proporción, cuarzos. La obtención de materias primas no habría requerido de mayor inversión de trabajo que la recolección del material dispuesto sobre la superficie o, en ocasiones semienterrado. En esta cantera se registraron áreas donde tuvieron lugar diversos eventos de la secuencia de producción lítica: reducción de núcleos, obtención de formas base, regularización de filos, mantenimiento, evidencia de reciclaje y reclamación y descarte. Esto, sumado a la presencia del arte rupestre y las estructuras arquitectónicas, nos llevaron a definir a RLS2 como cantera-taller, entendida como un espacio multipropósito (Somonte y Baied, 2018).

Entendemos que los ámbitos de aprovisionamiento lítico son lugares sumamente dinámicos y transitados, en los que se presentan contextos arqueológicos específicos que dan cuenta del amplio espectro de actividades que, muchas veces, acompañan a la obtención y explotación de un recurso determinado. En el caso de las rocas, su disponibilidad bajo diversas formas abre una puerta interesante a la variabilidad en las estrategias de obtención implementadas por las sociedades en el pasado. La presencia en RLS2 de bloques de tamaños variables (algunos difíciles de transportar por un individuo), pautó la forma de explotación y uso de estos recursos, dando lugar a estrategias diferentes. Por un lado, involucró la extracción, ya que se observó la fragmentación de grandes bloques de piedra no transportables, y también la recolección de rocas transportables, como los bloques pequeños y rodados que fueron utilizados en el mismo ámbito de la cantera. Por otro lado, la dinámica en la obtención de recursos estuvo dada, además, por el empleo y explotación de recursos en el largo plazo, donde las áreas de obtención constituyeron un reservorio de materia prima dentro de la misma cantera, al actuar como fuentes terciarias (sensu Church, 1995). En este contexto, cabe plantear que RLS2, además de lugar de aprovisionamiento de materia prima, ofreció paralelamente un stock flexible de materiales líticos, en su condición de cantera-taller.

En este punto es necesario hacer alusión a los efectos de la erosión eólica sobre la visibilidad de los restos arqueológicos que yacen sobre superficies sobreelevadas y expuestas. La erosión deja al descubierto materiales arqueológicos antes sepultados, que quedan disponibles para ser reutilizados desde su depositación original. La literatura se refiere a este tipo de uso secundario (Schiffer, 1987) con el término de scavenging entendiéndolo como una práctica alternativa de aprovisionamiento de materia prima lítica (Camilli y Ebert, 1992; Schiffer, 1987; Schlanger, 1992). Esto es relevante en el área de estudio, si se considera que la misma presenta un riesgo de erosión eólica severo a grave evidenciado por la presencia de erosión en pedestal (Collantes y González, 2012; Sayago et al., 1998; Sayago et al., 2012). En este contexto, la evidencia de reclamación observada en los artefactos líticos indica que ésta fue una práctica incorporada y sostenida a partir del 9000 AP y durante el Holoceno medio y tardío, como parte de las estrategias de aprovisionamiento en RLS2 (Somonte y Baied 2018).

\section{La arquitectura y el arte rupestre: acerca de la persistencia en el 'uso' de RLS2}

El largo plazo en el uso de RLS2 también se puede ver desde otros componentes del registro arqueológico, como la arquitectura y el arte rupestre. Estos suman a la discusión aspectos relacionados con la presencia y el tiempo de permanencia de las personas o grupos que visitaron/ocuparon la cantera-taller. Las características de las construcciones en RLS2 muestran cierta redundancia, 
ya que se trata de un registro arquitectónico repetitivo en contenido. La mayor parte de las estructuras comparten un patrón constructivo, que se mantuvo a lo largo del espacio y del tiempo. Este patrón está caracterizado por el uso de rocas sin cantear, sin argamasa, al ras del suelo y es compartido por los tipos morfológicos circulares, semicirculares o en forma de herradura o " $U$ ", lineales, etc. Este fenómeno se repite en casi toda la extensión de RLS2, salvo casos excepcionales (sólo 3 estructuras), donde los muros alcanzan una altura algo mayor, pero siempre menor al metro. Además, la "expeditividad" reflejada en las estrategias constructivas de gran parte de estas estructuras puede ser vista, además, en la falta de mantenimiento o modificación de las mismas.

Independientemente de la inversión de trabajo sobre lo arquitectónico, la presencia de instalaciones sugiere que aquellos que estuvieron en RLS2 tuvieron la necesidad de construir algún tipo de infraestructura relacionada con su permanencia allí y, por ende, con el acondicionamiento de algún sector para el pernocte y otras actividades afines. Sondeos realizados en campañas anteriores en tres de estas estructuras permitieron recuperar escasos carbones en una de ellas; mientras que en las otras dos no hubo material arqueológico. En este contexto, las estructuras pequeñas de forma circular y semicircular (Tabla 3), pueden estar relacionadas con el pernocte; el procesamiento y preparación de alimentos, con fogones y, también, con almacenamiento y acopio de recursos, entre otras. Arquitectura con características muy similares a las mencionadas, ha sido registrada en contextos específicos de aprovisionamiento lítico de la puna y pampa de la Argentina (i.e. Bobillo, 2019; Bobillo y Hocsman, 2015; Colombo, 2013) y la región costera del norte de Chile (i.e. Blanco et al., 2010).

Lo anterior nos invita a considerar, en primera instancia, que las ocupaciones en RLS2 pudieron haber sido de carácter transitorio o temporario, aún en el largo plazo de uso de ese espacio. Esto se relaciona con nuestra propuesta acerca de la continuidad temporal de la funcionalidad de RLS2 en términos de conjuntos artefactuales de filos específicos, relacionados a la explotación de determinados recursos, cuya necesidad y disponibilidad tuvo cierto continuum en el tiempo (Somonte y Baied, 2018). Las actividades relacionadas con esta persistencia en el uso del espacio, no parecen haber requerido de estadías prolongadas, al menos desde un punto de vista de una mayor inversión de trabajo sobre la infraestructura.

Además, elementos arquitectónicos como las estructuras lineales, monticulares, las acumulaciones menores de roca (¿mojones?) y, por otro lado, los caminos o las sendas, pudieron haber formado parte de la logística dentro de RLS2. La presencia de elementos arquitectónicos -construidos o no- pudieron haber servido para marcar rutas u otros componentes en función de cierta logística relacionada con el transporte de materiales hacia otras localizaciones extra-cantera y, también, al tránsito de personas y movimiento o circulación de recursos dentro del mismo ámbito de la cantera (Bloxam, 2009; Bloxam, y Heldal, 2008; Heldal, 2009). El aspecto logístico cobra relevancia para nuestro caso de estudio desde el punto de vista de la extensión de RLS2, ya que se tratan de más de 620 has. -delimitadas arbitrariamente- cuyo uso pudo requerir elementos que marquen, ordenen u orienten la circulación.

En este contexto, ¿cómo se integra el arte rupestre? Esta manifestación, entendida como una forma de expresión con connotaciones sociales, simbólicas e ideológicas, pudo servir para comunicar y marcar la presencia de determinadas personas o grupos en RLS2. Adris (2013) ha identificado cinco series cronológicas o momentos de ejecución de las representaciones, donde si bien hay ausencia de solapamiento de motivos, estos se presentan en forma de reciclado y de mantenimiento parcial de las representaciones. La autora estableció la coexistencia de bloques con grabados de las distintas series cronológicas de las representaciones rupestres que dan cuenta de, al menos, cinco lapsos temporales de ocupación en estos espacios. Registró la reutilización del soporte y/o de las representaciones, utilizando o incorporando los motivos preexistentes a una nueva concepción del espacio. Esto advierte, más allá de la persistencia en la ocupación de RLS2, cierta continuidad y mantenimiento de motivos a través del tiempo.

La asociación del arte con estructuras arquitectónicas circulares o semicirculares como así también con aquellas construcciones y modificaciones del paisaje asociadas probablemente a la logística (estructuras lineales, monticulares, mojones, sendas, etc.), pone de manifiesto el contexto de visibilidad que tuvo el arte en RLS2 al estar en espacios de posible tránsito y pernocte.

Profundizando en las actividades desarrolladas en RLS2, debemos señalar la ausencia de artefactos, como puntas de proyectil, que actúen como indicadores directos de tareas de caza de grandes animales. Esto indicaría, en primera instancia, que las actividades que formaron parte de este espacio multipropósito no tuvieron relación directa con este aspecto de la subsistencia.

A su vez, la inexistencia de estructuras agrícolas como sistemas de andenería; canales de riego o artefactos como manos y morteros, también impide proponer la realización concreta de actividades vinculadas con la producción de alimentos. Asimismo, tampoco hemos registrado materias primas líticas alóctonas (i.e. obsidiana) que permitan postular el tránsito interregional en RLS2. Esta ausencia de evidencia no necesariamente debe ser interpretada como inexistencia de esas actividades, ya que pudieron estar presentes en alguno de los momentos de uso de ese espacio. La profundidad temporal de las 
ocupaciones, desde finales del Pleistoceno, ha generado un palimpsesto complejo que dificulta una interpretación integral e inequívoca de la evidencia arqueológica, así como también impide una explicación a la ausencia de evidencia. En un contexto de persistencia ocupacional, no podemos dejar de lado aspectos relacionados con la intensidad y continuidad en el uso de un espacio. En este sentido, reconocemos que pudieron desarrollarse actividades de las que hoy no poseemos evidencia, debido a una baja intensidad en su ejecución y cuyo registro quedó desdibujado por otras actividades de mayor intensidad y continuidad temporal.

Las características repetitivas de la arquitectura, de los conjuntos instrumentales, así como los resultados preliminares de análisis funcionales y de residuos, invitan a no descartar el rol que pudo tener la recolección de vegetales y la explotación de recursos maderables, por parte de grupos diversos de la quebrada del río Amaicha y otras quebradas vecinas, quienes pudieron acceder de manera directa o indirecta a estos recursos (Germano et al., 2019; Ojeda Pérez, 2019; Oliszeswki y Arreguez, 2015). Estas visitas pudieron requerir de estadías cortas y explicarían la existencia de estructuras arquitectónicas de uso efímero como las comentadas. Paralelamente, el movimiento, traslado y acopio de los recursos explotados en ese ámbito, también pudo requerir de cierta logística y comunicación, evidenciada a través de estructuras monticulares, mojones, lineales y sendas, así como a través del arte rupestre. En este sentido, resulta razonable proponer que dentro del ámbito de RLS2, pudo darse un uso intensivo del espacio que habría involucrado cierta circulación, de carácter local, por parte de personas o grupos de personas.

Horco Molle, 19 de junio de 2020

\section{Agradecimientos}

A los colegas/amigos que participaron en el trabajo de campo: Marco Giusta, Alexis Coronel, Flavia Germano, Luis Monti, Jorge Funes y Alfredo Calisaya. A la Comunidad de Amaicha del Valle, por permitirnos ser $y$ hacer en estos paisajes arqueológicos maravillosos. Este trabajo se realizó en el marco de los proyectos PIUNT2018-G-606: Arqueología de necesidad y urgencia. Investigación y rescate en la vertiente occidental de Cumbres Calchaquíes, Tucumán, Argentina y PICT-20143448: Ocupaciones humanas del Holoceno medio y tardío en valles intermontanos del NOA. A los revisores anónimos del manuscrito, les agradecemos sus valiosos aportes y comentarios, ya que colaboraron a mejorar la versión final de este trabajo. No obstante, los errores $u$ omisiones son responsabilidad exclusiva de los autores.

\section{Bibliografía}

Adris, S. I. (2012). El arte rupestre entre cazadores y agricultores... paisaje ritual en Cumbres Calchaquíes y su vertiente occidental (Amaicha del Valle, Tucumán, Argentina). Actas del Congreso Internacional Arqueología y Arte Rupestre (SIARB, IFRAO), 25-29.

Adris, S. I. (2013). El Arte rupestre en espacios persistentes de Amaicha del Valle (Tucumán, Argentina). Mundo de Antes 8: 35-59.

Adelsberger, K.; Smith, J. R.; McPherron, S. P.; Dibble, H. L. Olszewski, D. I.; Schurmans, U. A. \& Chiotti L. (2013). Desert pavement disturbance and artifact taphonomy: A case study from the Eastern Lybian Plateau, Egypt. Geoarchaeology 28: 112-130. https://doi.org/10.1002/ gea. 21431

Aldersberger, K. \& Smith J. (2009). Desert pavement development and landscape stability on the Eastern Libyan Plateau, Egypt. Geomorphology 107: 178-194. doi: 10.1016\%2Fj.geomorph.2008.12.005

Aschero, C. A. (1975). Ensayo para una clasificación morfológica de artefactos líticos aplicada a estudios tipológicos interpretativos. Informe inédito presentado al CONICET.

Baied, C. A. (2017). Informe de Estudio de Impacto Arqueológico. Etapa 1: Línea De Base Propuesta de Instalación Planta Fotovoltaica de $100 \mathrm{Mwac}+100$ Mwac. Informe inédito presentado a NEOEN Argentina S.A.

Baied, C. A. \& Somonte, C. (2013). Mid-Holocene Geochronology, Palaeoenvironments and Occupational Dynamics at Quebrada de Amaicha, Tucuman, Argentina. Quaternary International 299: 80-89. https://doi. org/10.1016/j.quaint.2012.11.025

Banning, E. B. (2002). Archaeological Survey as Optimal Search. En G. Burenhult \& J. Arvidsson (Eds). Archaeological Informatics: Pushing The Envelope. CAA2001. Computer Applications and Quantitative Methods in Archaeology. BAR International Series 1016: 341-350. Oxford, England: Archaeopress.

Banning, E. B.; Hawkins A. L. \& Stewart S. T. (2006). Detection Functions for Archaeological Survey. American Antiquity, Vol. 71(4): 723-742. https://doi. org/10.2307/40035886

Barton, H. (2003). The Thin Film of Human Action: Interpretations of Arid Zone Archaeology. Australian Archaeology 57: 32-41. https://doi.org/10.1080/03122 417.2003.11681760

Blanco, J., M. de la Maza \& Rees C. (2010). Cazadores recolectores costeros y el aprovisionamiento de recursos líticos. Perspectivas interpretativas de los eventos de talla 
en el desierto absoluto. Werkén 13:45-68.

Bloxam, E. G. (2009). New directions in identifying the significance of ancient quarry landscapes: four concepts of landscape. En N. Abu-Jaber; E. G. Bloxam; P. Degryse \& Heldal, T. (Eds.), QuarryScapes: Ancient stone quarry landscapes in the Eastern Mediterranean (Vol. 12, pp. 165-183). Trondheim, Norway: Geological survey of Norway (NGU).

Bloxam, E. y Heldal, T. (2008). Identifying heritage values and character-defining elements of ancient quarry landscapes in the Eastern Mediterranean: An integrated analysis. En QuarryScapes. Conservation of Ancient Stone Quarry Landscapes in the Eastern Mediterranean. Work Package 8, Deliverable $N^{\circ} 10$. European Union.

Bobillo, F.M. \& Hocsman, S. (2015). Mucho más que solo aprovisionamiento lítico: actividades en canteras y prácticas sociales en las fuentes de Pampa Oeste, Quebrada Seca y Punta de la Peña (Antofagasta de la Sierra, Catamarca). Revista del Museo de Antropología 8: 23-44. https://doi.org/10.31048/1852.4826.v8.n1.11458

Carbonelli, J. P. (2014). Evidencias paleoambientales y de producción lítica en la cantera taller Ampajango, Valle de Yocavil (Catamarca, Argentina). La Zaranda de Ideas 11: 9-26.

Civalero, M. T. \& Franco, N. V. (2003). Early human occupations in western Santa Cruz province, southernmost South America. Quaternary International 109-110: 77-86. https://doi.org/10.1016/S1040-6182(02)00204-5

Colombo, M. (2013). Los cazadores recolectores pampeanos y sus rocas. La obtención de materias primas líticas vista desde las canteras arqueológicas del centro de Tandilia. (Tesis doctoral inédita). Universidad Nacional de La Plata, Argentina.

Collantes, M. M. \& González L. M. (2012). Mecanismos del proceso de desertificación en el valle de Santa María, provincia de Tucumán (Argentina). Acta Geológica Lilloana 24 (1-2): 108-122.

Dorn, R.I. (2009). The rock varnish revolution: New insights from microlaminations and the contributions of Tanzhuo Liu. Geography Compass 3: 1804-1823. https:// doi.org/10.1111/j.1749-8198.2009.00264.x

Dorn, R.I. (2007). Rock Varnish. En D. J. Nash y S. J. McLaren (Eds). Geochemical sediments and landscapes: 246-297. London: Blackwell.

Dorn, R. I. (2004). Experimental approaches to dating petroglyphs and geoglyphs with rock varnish in the California deserts: current status and future directions. En M. Allen y J. Reed (Eds). The human journey $\&$ ancient life in California's deserts: Proceedings from the 2001 Millennium Conference (pp. 211-224). Ridgecrest, California: Maturango Museum

Dunnell, R. C. (1992). The notion site. En J. Rossignol y L. Wandsnider (Eds.) Space, Time, and Archaeological Landscapes: 21-41. New York: Springer.

Dunnell, R. C. \& Dancey W. S. (1983). The siteless survey: Regional scale data collection strategy. En M. B. Schiffer (Ed). Advances in Archaeological Method and Theory 6: 267-287. New York: Academic Press:

Ebert, J. I.; Larralde S. \& Wandsnider L. A. (1987). Distributional archaeology: Survey, mapping, and analysis of surface archaeological materials in the Green River Basin, Wyoming. En A. J. Osborn \& R. C. Haskell (Eds). Perspectives on archaeological resources management in the Great Plains: 159-178. Omaha, Nebraska: I and O Publishing.

Germano, F. M. (2016). Análisis funcional de instrumentos líticos barnizados en superficies arqueológicas de Río Las Salinas, Amaicha del Valle Tucumán. Serie monográfica y didáctica 54: 2612.

Germano, F. M.; Somonte, C. \& Albornoz, P.L. (2017). Análisis de microrrestos vegetales en filos de artefactos líticos cubiertos por barniz de las rocas (Amaicha del Valle, Tucumán, Argentina). Serie Monográfica y Didáctica $N^{\circ}$ 1: 43

Heldal, T. (2009). Constructing a quarry landscape from empirical data. General perspectives and a case study at the Aswan West Bank, Egypt. En Abu-Jaber, N., Bloxam, E., Degryse, P. y Heldal, T. (Eds.), QuarryScapes: ancient stone quarry landscapes in the Eastern Mediterranean. Geological Survey of Norway Special publication 12: 125-153. Noruega: Geological Survey of Norway.

Heldal, T. \& Bloxam, E. (2008). Identifying heritage values and character-defining elements of ancient quarry landscapes in the eastern Mediterranean: An integrated analysis. En QuarryScapes. Conservation of ancient stone quarry landscapes in the

Eastern Mediterranean. Work Package 8, Deliverable $N^{\circ}$ 10. Trondheim, Norway: The Geological Survey of Norway (NGU).

Hermanns, R. and M. Strecker (1999). Structural and lithological controls on large Quaternary rock avalanches (sturzstroms) in arid northwestern Argentina. Geological Society of America Bulletin 111: 934-948. https://doi. org/10.1130/0016-7606(1999)111\%3C0934:SALCOL\% 3E2.3.CO;2

Liu, T. (2003). Blind testing of rock varnish microstratigraphy as a chronometric indicator: Results 
on late Quaternary lava flows in the Mojave Desert, California. Geomorphology 53: 209-234. https://doi. org/10.1016/S0169-555X(02)00331-8

Liu, T. \& Broecker W. S. (2008). Rock varnish microlamination dating of late Quaternary geomorphic features in the drylands of western USA. Geomorphology 93: 501-523. https://doi.org/10.1016/j.geomorph.2007.03.015

Liu, T. \& Broecker, W. S. (2008). Rock varnish evidence for latest Pleistocene millennial-scale wet events in the drylands of western United States. Geology 36, 403-406. https://doi.org/10.1130/G24573A.1

Liu, T. \& Broecker, W. S. (2007). Holocene rock varnish microstratigraphy and its chronometric application in the drylands of western USA. Geomorphology 84: 1-21. https://doi.org/10.1016/j.geomorph.2006.06.008

Liu, T. \& Broecker, W. S. (2000). How fast does rock varnish grow? Geology 28: 183-186. https://doi. org/10.1130/0091-7613(2000)28\%3C183:HFDRVG\%3 E2.0.CO;2

Liu, T. \& Dorn R. (1996). Understanding spatial variability in environmental changes in drylands with rock varnish microlaminations. Annals of the Association of American Geographers 86: 187-212. https://doi. org/10.1111/j.1467-8306.1996.tb01750.x

Martínez, J. G.; Mauri, E.; Mercuri, C.; Caria, M. \& Oliszewski, N. (2013). Mid-Holocene human occupations in Tucumán (Northwest of Argentina). Quaternary International 307: 86-95. https://doi.org/10.1016/j. quaint.2013.04.027

Matmon, A.; Simhai, O.; Amit, R; Haviv, I; Porat, N.; McDonald E. L.; Benedetti, L. \& Finkel R. (2009). Desert pavement coated surfaces in extremedeserts present the longest lived landforms on Earth. Geological Society of America Bulletin 121(5-6): 688-697. doi: 10.1130/ B26422.1

Nami, H. G. (1992). El subsistema tecnológico de la confección de instrumentos líticos y la explotación de los recursos del ambiente: una nueva vía de aproximación. Shincal 2: 33-53. Escuela de Arqueología. Universidad Nacional de Catamarca.

Mon, R. \& Mansilla N. 1998. Estructura geológica del territorio de la provincia de Tucumán. En M. Gianfrancisco; M. E. Puchulu; J. Durango de Cabrera \& G. P. Aceñolaza (Eds). Geología de Tucumán (pp. 147-153). San Miguel de Tucumán, Argentina: Colegio de Graduados en Ciencias Geológicas de Tucumán,

Oliszewski, N. \& Arreguez G. (2015). Manejo de recursos vegetales alimenticios en la Quebrada de los Corrales, El
Infiernillo, Tucumán (2100-1550 años AP). Comechingonia 19(2): 111-140. https://doi.org/10.37603/2250.7728.v19. n2.18134

Plog, S.; Plog F. \& Wait, W. (1982). Decision making on modern surveys. En M. Schiffer (Ed.). Advances in Archaeological Method and Theory, Vol. 1 (pp. 383-421). New York: Academic press.

Sayago, J. M.; Collantes M. M. \& Niz, A. (2012). El umbral de resiliencia del paisaje en el proceso de desertificación de los valles preandinos de Catamarca (Argentina). Acta geológica Lilloana 24 (1-2): 62-79.

Sayago, J. M.; Collantes, M. M. \& Toledo, M. A. (1998). Geomorfología. En M. Gianfrancisco; M. E. Puchulu; J. Durango de Cabrera \& G. Aceñolaza (Eds). Geología de Tucumán: 241-258. $2^{\circ}$ Edición. San Miguel de Tucumán: Colegio de Graduados en Ciencias Geológicas de Tucumán.

Schiffer, M. (1987). Formation processes of the archaeological record. Albuquerque, New Mexico: University of New Mexico Press.

Schlanger, S. (1992). Recognizing persistent places in Anazasi settlement systems. En J. Rossignol \& L. Wandsnider (Eds). Space, time, and archaeological landscapes (pp. 91-122). New York: Springer

Schiffer, M.; Sullivan A. \& Klinger T. (1978). The design of the archaeological surveys. World Archaeology 10 (1): 1-28. https://doi.org/10.1080/00438243.1978.9979712

Sesma, P.; Guido E. \& Puchulu, M. E. (1998). Clima de la provincia de Tucumán. En M. Gianfrancisco; M. E Puchulu.; J. Durango de Cabrera \& G. P. Aceñolaza (Eds). Geología de Tucumán (pp. 41-46). San Miguel de Tucumán: Colegio de Graduados en Ciencias Geológicas de Tucumán.

Somonte, C. \& Baied, C. A. (2017). El palimpsesto como una puerta de acceso a diferentes temporalidades: el caso de Río Las Salinas 2 (Tucumán, Argentina). Estudios Atacameños 55: 35-55. http://dx.doi.org/10.4067/ S0718-10432017005000014

Somonte, C. \& Baied, C. A. (2018). Ocupaciones humanas de finales del Pleistoceno en valles intermontanos del noroeste Argentino. Materialidades 5: 1-21. https://doi. org/10.22307/2340.8480.2017.01.001

Somonte, C. y Baied, C. A. (2011). Recursos líticos, aprovisionamiento y aspectos temporales de fuentes de abastecimiento en Amaicha del Valle, Tucumán, Argentina. Comechingonia 14: 81-97. https://doi. org/10.37603/2250.7728.v14.n1.17902 
Somonte, C. \& Baied, C. A. (2013). Edad mínima de exposición de superficies en canteras-taller: Reflexiones en torno a las primeras dataciones mediante microlaminaciones del barniz de las rocas (VML) para el Noroeste Argentino. Chungara 45 (3): 427-445. http:// dx.doi.org/10.4067/S0717-7356201300030000

Strecker, M. R.; Cerveny, P.; Bloom, A. L. \& Malizzia, D. (1989). Late Cenozoic tectonism and landscape development in the foreland of the Andes: Northern Sierras Pampeanas, $26^{\circ}-28^{\circ} \mathrm{S}$, Argentina. Tectonics 8:
517-534. https://doi.org/10.1029/TC008i003p00517

Tineo, A. (2005). Estudios hidrogeológicos del valle del río Santa María, Provincia de Catamarca. Serie Correlación Geológica 20. San Miguel de Tucumán: Instituto Superior de Correlación Geológica - CONICET.

Wandsnider L. A. \& Camilli, E. (1992). The Character of Surface Archaeological Deposits and Its Influence on Survey Accuracy. Journal of Field Archaeology 19(2): 169188. https://doi.org/10.1179/009346992791548914. 